\title{
Investigating Indonesian Teachers' ZAD in the Representation of Fractions
}

\author{
Rustanto Rahardi, Edy Bambang Irawan, Santi Irawati \\ Department of Mathematics, Faculty of Mathematics and Natural Sciences \\ State University of Malang \\ Malang, Indonesia
}

\begin{abstract}
This article aims to formulate the alternative of coherently integrated steps of learning fractions for elementary schools based on the analysis of subjects' ability. The subjects consist of 33 university students (future elementary school teachers), 29 elementary teachers spread out in Indonesia, and an elementary school teacher model. The analyzed abilities are the possibilities of difficulty and misunderstanding, and the order of learning steps of the relevant topics. The subjects' abilities were seen as being in a Zone of Actual Development (ZAD). Data were taken from the procedures of fraction problem-solving, questionnaires consisting of open questions, and the description of the classroom learning that was then analyzed qualitatively. The results showed that based on the ZAD analysis, the subjects have not been able to integrate a concrete representation with the general properties of the symbolic representation. Such identification and the integrated literature review resulted in the formulation of a learning step called as Theoretical Discussion.
\end{abstract}

Keywords: ZAD, representing, fraction

\section{INTRODUCTION}

The topic of fractions in math is difficult for elementary students [1], [2]. Meanwhile, Pinilla [3] concluded that fractions are one of the most studied questions in Mathematics Education and fraction learning is one of the contributing factors in students' failure. It has been widely known that, in traditional learning, elementary school teachers lack the ability to encourage their students to understand the meaning of fractions. Teachers frequently teach fractions through the rules, definitions, and procedures that exist in the fractional numbers to be memorized by students. Based on interviews with some elementary school teachers, they agreed that the teaching of mathematics should be meaningful. The contributing factor in meaningful teaching is the ability of teachers to teach with various activities, such as through experiments through the concrete world, write.

ng on the board, and clarifying the expected points [4]. Students will love learning through thereal world because it is a subject that builds their reasoning [5]. Students' learning outcomes improve when teachers use concrete objects in the classroom [6]. The learning model through the representation of concrete objects as learning media is rarely applied in the classroom. Teachers pointed out a cliché for such fact regarding the curriculum demand and the limited time. Therefore, it is necessary to have coherently integrated steps which are effective to be implemented in learning.
There are still weaknesses of the real media use by teachers in some developed countries. Ma [7] found the lack of teacher ability to use real media in the US. Their ability to teach by using the representations of real media was still low. Fyfe et al [8] suggested the need for using actual media in teaching the early material and subsequently makes it more explicit and abstract. In his research, Sousa [9] concluded that the most efficient sequence of the new representation of mathematics teaching is through the concrete-pictorial-abstract (CPA) model. The results of this study are supported by [10] stating that learning would be effective based on those three stages in CPA. Daly \& BlakeneyWilliams [11] opinion confirmed the needs of pictorial use in the form of picture books that can provide access to students' learning perspective. One of the benefits offered by picture books is to ease the student comprehension of the presented foreign concepts.

The abstract can explicitly be split into two parts, i.e. symbolic and symbolic general properties. Lamon [12] described the results of the students' pictorial-symbolic representation model of fractions, but he has not given the descriptions of the symbolic general properties. In his research, Gujarati [13] only discussed about a certain/specific case of $(26+35=61)$, starting from a base of 10 concrete blocks, continued by the image of the blocks, and followed by a stackable summation, but he has not described the generalization. The above articles of [12], [13] indicated that they have not discussed the generalization of procedural, symbolic general properties, whereas generalization is necessary to understand or solve math problems without using concrete or pictorial representations. Generally, the application of special CPA representation model of fractions is illustrated in Fig. 1. As described above, there have been discussions of several translations of concrete-pictorial-symbolic (CPS) model representation, but the symbolic translations into the general properties of fractions have not been discussed yet. In this context, general properties are the rules of computing that are attached to mathematical symbols and familiarity with the operating procedure in general. The purpose of the discussions about these general properties is to solve problems concerning fractions as abstract objects. 


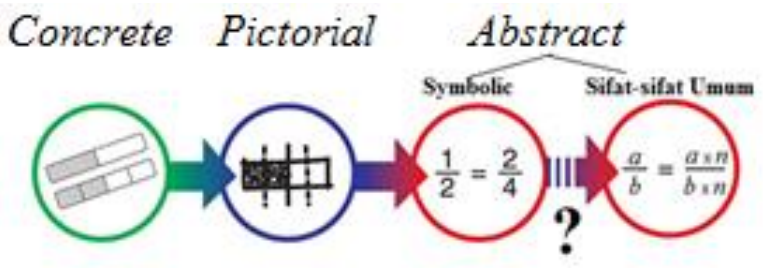

Fig. 1. There is lack of discussion about symbolic to general properties

Before teaching in the classroom, teachers are required to master teaching skills and it is also important to prepare an effective lesson plan. This preparation will be effective if the teachers have basic abilities to sustain the demands. In this study, such initial capabilities possessed by teachers are categorized as ZAD. Through specific learning activities, the fundamental knowledge of teachers is used as the basis to develop their ability in teaching fractions. Such initial ability is necessary to be investigated for facilitating an innovative pedagogicdevelopment of teachers [14]. Based on the research of [3], [7]-[9], which have been explained above, this study specifically aimed to discuss the teachers' ZAD about fractions in Indonesia. The description of the results led to the theoretical translation of each integrated CPA representation model. Furthermore, this formulation was reported as a theoretical discussion result, and the implementation of this formula can be followed up with classroom practice to test its effectiveness. The test of effectiveness is necessary in order not to cause difficulties for learners related to the material [15].

\section{METHODS}

This research modifies Wademan research design [16], which is divided into three steps. The first step is data collection. In this step, the researcher collects data by observing the fraction operational ability of students (future elementary school teachers), doing clinical interviews with elementary school teachers as practitioners on how they teach the concept of fractions, and performing a direct observation on fractions learning in the classroom of an elementary school. The data obtained from this step is in the form of teachers' ZAD and the issues discussed in this article can be clearly identified based on such data. ZAD identification is necessary because it is a powerful management that can describe effective teachers [17]. The second step of the analysis is identifying the integration of translational representation steps taken by the research subjects, followed by collecting the supporting literature as the materials to compose the translation of integrated representations, and then followed by consulting the translational integration with experts and practitioners. The third step establishes the formula and principles of the integrated representation design as a temporary product approach. In this article, the temporary product is called as Theoretical Discussion.

\section{DATA COLLECTION AND ANALYSIS}

The research subjects consisted of 33 university students (future elementary school teachers), 29 elementary school teachers who are distributed through East Java, and a model of elementary school teacher. The data obtained from 33 future elementary school teachers were focused on those who made mistakes in fractions operational procedures in mathematical problem-solving. The data obtained from 29 primary teachers were focused on the sequence of representation procedures of the answers through the clinical interview. Additionally, the data gathered from a model of the elementary school teacher were in the form of transcriptions of the reduce footage of teaching in the classroom.

\section{A. Future Elementary School Teachers' ZAD}

The subjects of observation were 33 future elementary school teachers who have not obtained their bachelor degrees in South Malang. They were taking an undergraduate program of Elementary School Teacher Education (Pendidikan Guru Sekolah Dasar) in some universities. Therefore they were referred to as future elementary school teachers. Their ZAD was identified from the way they procedurally solve a fractions problem given in the course of Mathematics Learning for elementary school. Four students solved the problem correctly, while the others had relatively similar mistakes. One sample problem that was solved in wrong procedures by a future teacher was illustrated inside the box in Fig. 2. The first box shows that the teacher eliminates half of the numerator and denominator, whereas the denominator is $\frac{1}{2} \sqrt{3}$ so the result should be $\frac{1}{\sqrt{3}}$ instead of $\sqrt{3}$. On the other hand, the second and third boxes showed a similar understanding concept of fractions division, i.e. one divided by any number would result in the number of the denominator. Based on interviews with those who had the procedural error, it was revealed that they were not able to interpret the concept of fractions correctly and they were not capable of using concrete objects to represent the interpretation of the concept of fractions. They had not mastered the fraction material well. In fact, the mastery of material has a significant effect on learning outcomes [18]. Such data became important findings on the future elementary school teachers' ZAD.
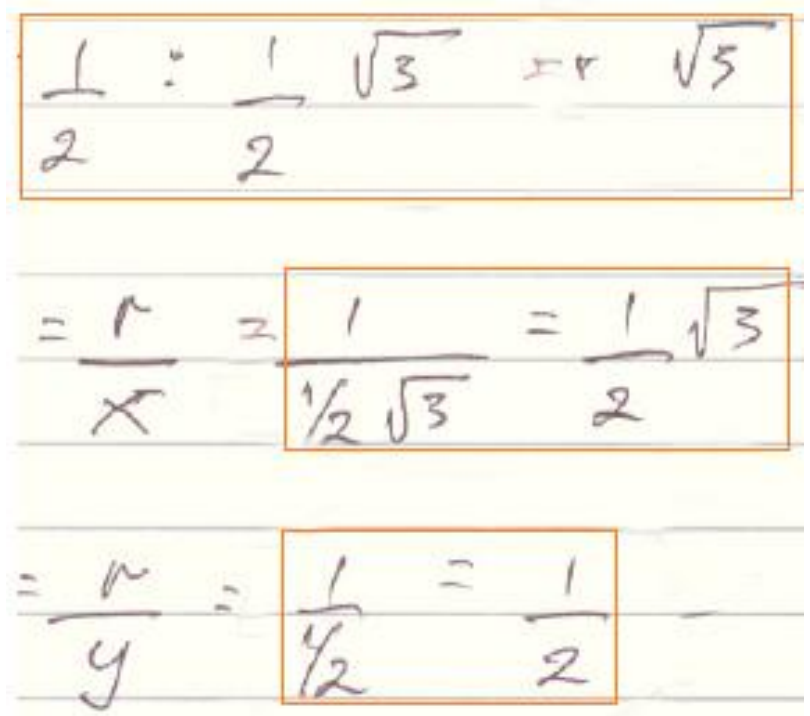

Fig. 2. Incorrect Procedures in Fraction Solution 
Such facts indicated many student failures in achieving the learning objectives of fractions material in elementary school. Interviews with some elementary school students who had been taught about fractions indicated that they were not advanced to master the concept of fractions even they could not represent the concept of fractions with concrete objects. Theywe're studying fractions at school procedurally.

\section{B. Fraction-Number Task Interview}

After performing observations towards the future elementary school teachers, the researchers then conducted a clinical interview about fractions learning to several elementary school teachers who were distributed across East Java. The interviews aimed to analyze teachers' ZAD about fractions, especially regarding the material of equivalent fractions. Such material is the second material given after the introduction of fractions. Teachers' ZAD observed from their representation in the clinical interview of the equivalent fractions, that is $\frac{1}{2}=\frac{2}{4}=\frac{3}{6}=\cdots$. The focus of the analysis was the translational representations used by the teachers from the beginning to the end, each representation they used, and the interconnection between representations when they taught fractions. The clinical interview subjects were 29 elementary school teachers spread over 13 cities and regencies in East Java, Indonesia, consisted of 10 male teachers and 19 female teachers. They were interviewed when they participated in professional training for elementary school teachers in Batu. The researchers did not know those teachers previously so the selection could fairly represent all teachers in East Java.

The results showed that the teachers began to explain about fractionsequivalent to a half through diverse representations, including concrete: 4 people, pictorial: 16 people, and symbol writing: 9 people.Some of those who started with the concrete representationsstarted the lesson by splitting apples into two equal parts, into four equal parts, and into six equal parts. The one-half apples were compared with two onefourth apples and three one-sixth apples; then their similar sizes were shown. After the concrete representations, there wasone teacher who continued with pictorial representation, two people continued with symbolic representation, and a person continued with perception representation. The results of representations are categorized as perception, since the teachers' representations did not correspond to the main problems, namely the equivalent fractions

For those who started with a pictorial representation, among others, by showing a rectangle divided into two congruent parts, four congruent parts, and six congruent parts respectively as the representations of a half, two-fourth, and three-sixth.15 subjects with correct results continued to the symbolic representation there was a person who continued improperly (perception). The data from these 15 people indicate that three people represented the symbol in the wrong way.

Nine teachers started the symbolic representations, six of them continued with procedural representations, and three of them showed perceptions. The used procedural representations were the properties of the equivalent fractions. The equivalent fractions could be obtained from multiplying or dividing each numerator and denominator by the number equal to the previously used fractions. The categorization of perception was based on the unclear procedures taken by the teachers since they did not understand fractions procedurally. Such finding is similar to the previous findings where 29 from 33 future elementary school teachers did not understand the concept of fractions. All representations which were ended with the symbolic representations only indicated that a half equals to twofourth and three-sixth, but has not shown the procedure of determining the equivalent fractions. The absence of the general procedures to determine the equivalent fractions found in the clinical interview was an important finding which became the main focus of this article. Fig. 3 shows the observation results of the teachers' representations as for their initialabilities or ZAD about the equivalent fractions.

One evidence summarized in Fig. 3 is the representation in Fig. 4 which shows a teacher's explanation about fractions equivalent to a half. He started using pictorial representations of fractions equivalent to a half which were categorized as perceptions. The first line in the figure explains that the rectangle is divided into two congruent parts and one part is shaded as the representation of a half. The second line describes the rectangular which has a different area with the rectangular in the first line, which isdivided into four congruent parts in which two of them are shaded as the representation of two-fourth. The third line explains the different rectangular area from those of the first and second rectangular, which are divided into six congruent parts and three of them are shaded as the representation of threesixth. The pictures which were regarded as the representations of one-half, two-fourth and three-sixth fractions did not show a similar integrity. The teacher had not understood the concept of fractions through pictorial representations. Thus, his representation showed his perception, so he did not conclude that those fractions are equivalent at the end of hisexplanation. The translation from pictorial to symbolic writing representation of the equivalent fractions was not available yet because he had not written the equivalent fraction representation. As a result, the general representations of the properties or procedures of equivalent fractions was not available. The data of representation categories in Fig. 3 shows the teacher's significant lack of ZAD of fractions.

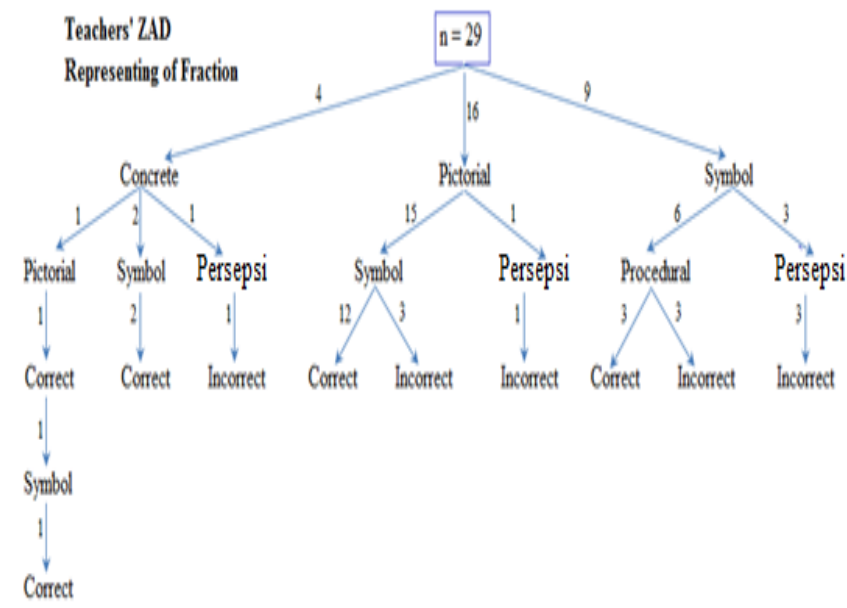

Fig. 3. Teachers' ZAD in Representing the Equivalent Fractions 


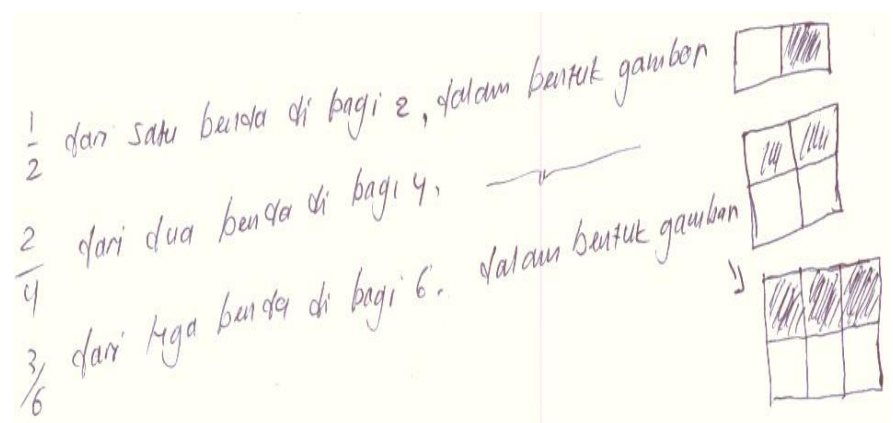

Fig. 4. Equivalent Fractions Perception of An Elementary School Teacher

\section{Observations of Fractions Learning}

Rahardi [19] has observed the learning process of equalizing the denominators of two fractions of the third graders in an elementary school and found a fragmentation of concrete to the general properties of the denominator equalization. The following is a reduction transcript of the fourth graders of elementary school's mathematical learning tape about "Changing Two Fractions with Different Denominators into Equal Denominators: $\frac{1}{3} \operatorname{and} \frac{2}{5}$ ". The teacher in such class is a woman who was called as Ustada. In this transcript, Ustadais abbreviated to $\mathrm{U}$ and students are abbreviated to $\mathrm{S}$. The transcript does not include the whole tape but only the important parts. A stick was utilized as the concrete material or concrete representation in this learning activity. The lesson began with reviewing students' understanding of fractions using a stick as a representation, and then the students should represent the fractions symbol orally.

- U: How do you call each part of the stick after it is divided into 12 equal parts?

- S:One-twelfth

Then, the Ustada changed the question conversely to discover the students' ability to interpret.

- U: If we call a part of a stick one-fiftieth, then how many times do I have to part the stick?

\section{- $\mathrm{S}: 50$}

The verbal representation activities to explore the students' ability about fractions were repeated until the Ustada considered the students to have already understood the concrete and verbal representations. The Ustada did not show any pictorial or symbolic representations of the discussed fractions. The Ustada continued the activities by discussing the equalization of two fractions with different denominators as follows.

- U: Well now I will ask again, for instance,I have ropes with sizes of $\frac{1}{3}$ and $\frac{2}{5}$, do you know what sizes of the ropes are so that they can be divided into those sizes?

The Ustada symbolically (abstractly) represented those two fractions on the board. The question in line (5) was not very clear, so the students were confused and therefore had various answers, line (6). However, if the next set of questions were considered, it can be identified that the purpose of such questions is to ask for an equalization of the denominators of $\frac{1}{3}$ and $\frac{2}{5}$.

- $\mathrm{S}: 6 ; 15 ; 30 ; 45 ; 60 ; 35$

- U:Some students answer 6, why?

- S: We do not know

- U:You have to remember that every answer must have a reason. Ok, so there are students who answer 15. Ok kids, if we have 15 , normally.... Let's try, so I have 3 and 5, now, let's find their LCM.

The line (9), from the data of fraction learning observation, shows that the Ustada answered herself and hence there was a disagreement. The Ustada originally used a stick as a representation to help the students in understanding fractions, but when it came to equalizing the denominators, she turned out using Least Common Multiple (LCM) procedures.

Based on the findings of future elementary school teachers' ZAD, teachers' ZAD data gathered from clinical interview, and a teacher's ZAD data obtained from fractions learning observation, as well as from the explanations in this data collection stage, it can be identified that the focal point of this article is the nonintegrated translation of the Concrete-PictorialAbstract. Especially the translation in representing the Abstract since the symbolical shift to its procedural properties has not been connected properly. The connection will result ineffective learning. Anthony \& Walshaw [20] promoted ten characteristics of effective learning. One of them is an effective teacher to support the students to create links between mathematics topics. The terms of mathematics topics in this article refers to the topic of concrete representation until abstract representation. In order to make such adequate connection, it is necessary to formulate the stages of linking.

\section{DATA INTERPRETATION}

As has been agreed above, mathematics learning in elementary school should be meaningful, initiated with the representations of concrete objects, and then explicitly and gradually become more abstract. The stages of representations must consider the level of abstraction owned by the students. According to Jean Piaget's intellectual development theory, 711 old year elementary school students are in their concrete operational stage. This theory became the framework of the opinion that students' original mathematics knowledge should be taught using concrete representations as manipulation objects. Manipulatives are used to promote conceptual understanding [21] and are frequently used to solve mathematics problems related to the concrete world. The results of research performed by [22] showed that students with high ability could generate various ideas in mathematics problem-solving. Otherwise, students with low ability would have great difficulties. Teachers who can support student conceptual understanding development are guaranteed to be able to fulfill the professional requirements [23].

Bruner [24] pointed out that each domain of knowledge could be represented in three types or categories, namely: (a) through action (enactive), (b) through visual images (iconic), 
and (c) through words and language (symbolic). Lesh et.al [25] extended the Bruner's categories into five kinds of representations, which are: (a) real world situations, (b) manipulative models, (c) pictures, (d) the spoken symbols, and (e) written symbols. Sousa [9], based on Bruner, called the learning approach that he proposed as Concrete-PictorialAbstract (CPA). Enactive activities describe the experiences and environment in cognitive development. According to such basis, teachers can start the lesson with a concrete problem, and then simplify the problems using the representation of manipulative models. These models are practice media for students and function as manipulative representations. Marley \& Carbonneau [26], in their perspective theory, concluded that the manipulative models are effective teaching tools. The concrete manipulative model will support the conceptual understanding of students with low ability, while students with the high ability can construct the abstract concept on their mind [22], [27]. The research conducted by [28] showed that in order to ease the representation of external knowledge, an irrelevant representation is necessary to be asimilar representation of the actual problem. The manipulative model representation of the realproblem should be followed by a manipulative model representation that does not represent such real problem. The general term in an irrelevant representation or representation that does not represent the actual problems is that there is a nonexample. It should be emphasized that among the real issues and manipulative translation models built with spoken words, there are given examples and non-examples in the manipulative models.

The use of concrete manipulative model representation is limited. Therefore, pictorial representation or diagram is used for wider purposes. Such representation is usually called as semi-abstract representation. Certain real problems can usually be solved by using this representation. Such representation is also limited since it can be used only for large fractions. This kind of limitation requires a simple representation. Mathematics has a role in addressing such issue through the creation of representation in the form of symbols which are commonlyreferred to as mathematical symbols. Such symbols represent the situation of the real problem in a more abstract way than the previous representations. Such particular issues can be solved abstractly through this representation of symbols. For example, certain problems of the fractions equivalent to one-half and two-forth can be solved by CPS through the representation of the manipulative models to the writing of the symbols, i.e. $\frac{1}{2}=\frac{2}{4}$.

Certain issues of fractions equivalent to the above have triggered many discussions, but there is not a more general discussion yet. Fractions are generally considered to be equivalent when the numerator and denominator of the first fraction are divided or multiplied by the same number other than zero. The translational process of the equivalent fractions from specific representation to general representation became an important discussion in this study. The translation from writing special symbols to general properties or procedures requires an inductive process. Bearing in mind that the representation of the spoken words is the dominant link in any other representations and it is necessary to provide examples and non-examples in every CPS representation.
Based on the analysis of integration identification in the second step and based on the opinions of teachers, practitioners, and discussion with experts, the third step is setting out the principles of CPA representation model integrity. Each original knowledge domain about fractions can be represented in seven types or categories, namely (a) real world situations, (b) manipulative models, (c) pictures or diagrams, (d) writing special symbols, (e) inductive, (f) mathematical symbols and procedures, and $(\mathrm{g})$ spoken words. The representation that combines each representation of (a) to (d) is the spoken symbols. The representation's sequence from (a) to (d) can vary based on the situation and conditions of the learning process in the classroom. The connectivity of (d) and (f) is the inductive process (e) which contains both spoken and written representation. Fig. 5 shows the representation flow theory as a result of the discussions in this article.

Sagala [29] stated that the context of the inductive learning process is a teaching approach that is initiated by presenting some special circumstances to be then concluded into a principle or rule. The inductive process can be started with the delivery of the cases, facts, examples, or reasons that reflect a concept or principle; then learners are guided to diligently synthesize, find, or conclude the basic principle of the lesson. Hence, students can infer from a phenomenon shown through special symbols. However, teachers should provide the students enough examples that have the same properties or rules. The examples are presented in varied ways from the simplest to the most difficult ones. Fig. 6 shows the flow of inductive thinking which instills a mathematical concept that has regular patterns.

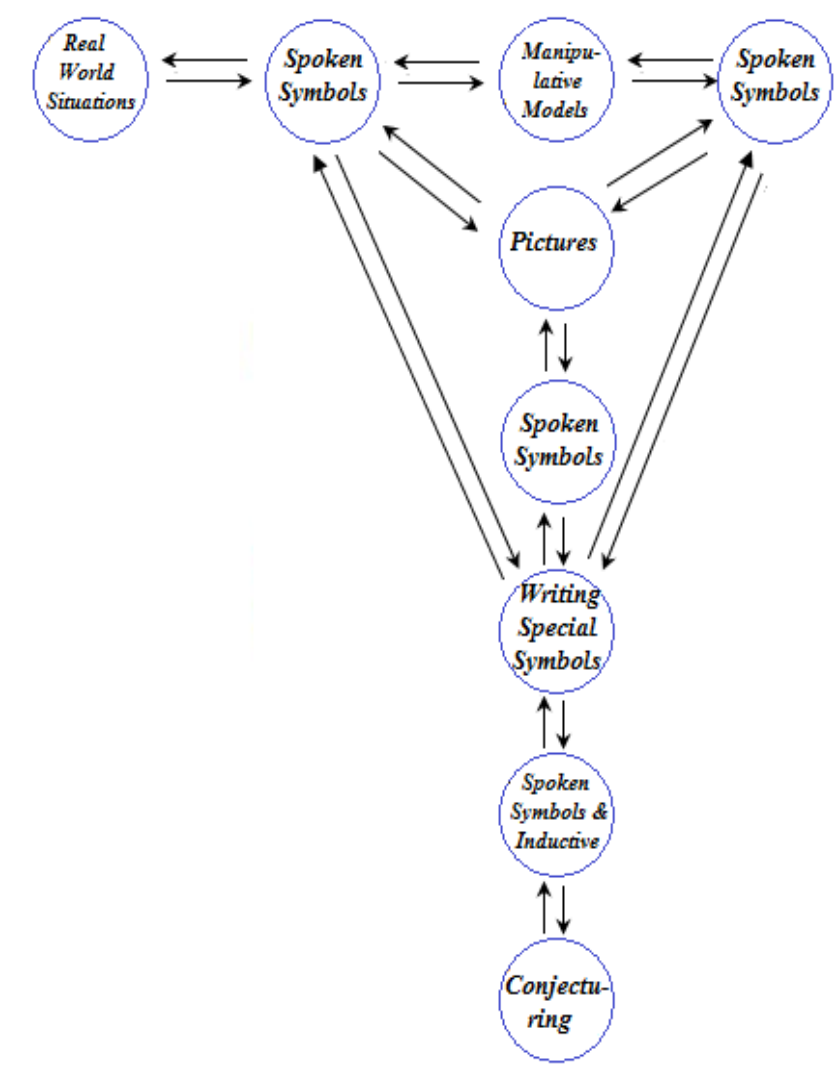

Fig. 5. Translation Design of Integration among the Representations in CPA 


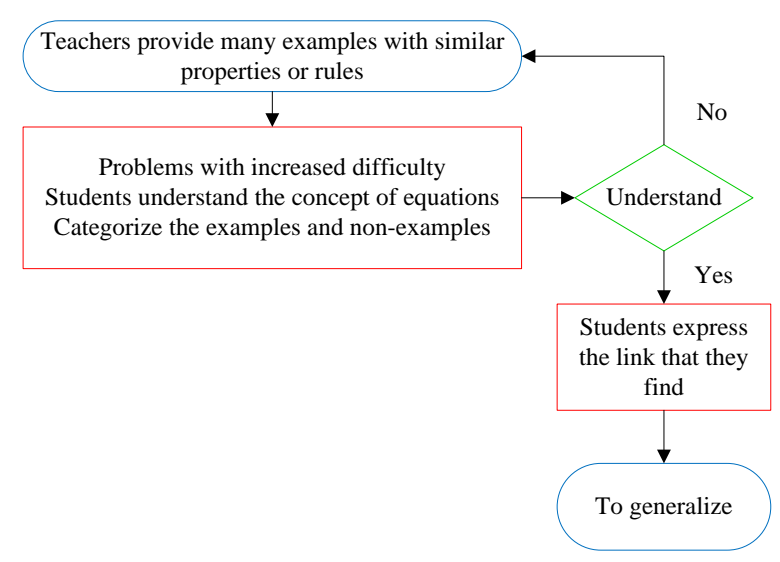

Fig. 6. Flow of Inductive Thinking

\section{DISCUSSION}

The representation flow theory resulted from the discussion presented in Fig. 5 needs to be implemented to test its effectiveness. Such level of effectiveness is important for teachers because it will affect the level of their students' knowledge [30]. In order to fit flow, the learning instruments should be carefully prepared by the teachers. The instrument schemes prepared by teachers affect students' conceptual understanding [31]. The test of effectiveness may be performed using a descriptive qualitative method based on the transcript of the flow implementation or via Classroom Action Research (CAR) method.

The description of the implementation results can be used to view the ZPD (Zone of Proximal Development) of a teacher by comparing it with the teacher's ZAD before the implementation. A teacher's ZAD is identified by clinical interview with the teacher and clinical interviews with several students, e.g. about the introduction of fractions. These students are the students who have been taught the fractions introduction material by the teacher. Therefore, the flow should be implemented on students who have never been taught the fractions introduction material. The descriptions of the teacher's promotion or action that has not taken previously resulted in students understanding of the material. Thus, the description of such promotion is the teacher's ZPD.

\section{CONCLUSION}

A meaningful teaching usually begins with concrete objects and gradually develops with the support of "semiconcrete" materials, such as images, and finally replacedby the use of symbolsor "abstract" and the students gain greater knowledge beyond the procedural knowledge through the CPA representation. Concrete objects used as manipulative materials of the actual problems given by the teacher. This article discusses the theory that combines the representation of the real world situation with the representation of mathematical symbols and the procedures. The discussion results of suchintegrated representation theory are formulated into seven principles ofthe integrated designs, i.e. (a) real world situations, (b) manipulative models, (c) pictures, (d) the writing of special symbols, (e) inductive, (f) mathematical symbols and their procedures, and (g) spoken words. The effectiveness of this theory needs to be tested in the classroom.

\section{REFERENCES}

[1] C. K. Leung, "A Preliminary Study on Hongkong Students' Understanding of Fraction," in 3rd Redesigning Pedagogy International Conference.

[2] A. G. Spinillo and M. S. S. C. Federal, "No Title," 2004.

[3] M. I. F. Pinilla, "Fractions: conceptual and didactic aspects.," Acta Didact. Univ. Comenianae, vol. 7, no. 2007, pp. 23-45, 2007.

[4] E. Bahcivan and W. W. Cobern, "Investigating Coherence among Turkish Elementary Science Teachers' Teaching Belief Systems, Pedagogical Content Knowledge and Practice," Aust. J. Teach. Educ., vol. 41, no. 10, pp. 63-86, 2016.

[5] P. D. Martino and R. Zan, "'Me and Maths': Towards a Definition of Attitude Grounded on Students' Narratives," J. Math. Teach. Educ., vol. 13, no. 1, pp. 27-48, 2010.

[6] R. J. Marzano, "Teacher Evaluation Model, Marzano Research Laboratory," 2013. [Online]. Available: http://tpep-wa.org/wpcontent/uploads/Marzano_Teacher_Evaluation_Model.pd. [Accessed: 29-Oct-2014].

[7] L. Ma, Knowing and Teaching Elementary Mathematics: Teachers' Understanding of Fundamental Mathematics in China and the United States. Mahwah, New Jersey: Lawrence Erlbaum Associates, Inc., 1999.

[8] E. R. Fyfe, N. M. McNeil, J. Y. Son, and R. L. Goldstone, "Concreteness Fading In Mathematics and Science Instruction: A Systematic Review," Educ. Psychol. Rev., vol. 26, no. 1, pp. 9-25, 2014.

[9] D. A. Sousa, How the Brain Learns Mathematics. Thousand Oaks, CA: Corwin Press, 2007.

[10] H. K. T. C. Halloluwa, A. P. Kaushalya, and P. K. B. P. S. Bandara, "Smart Interactive Comprehensive Learning Aid: Practical Application of Bruner's Theories in Primary Education," Int. J. Sci. Eng. Res., vol. 2, no. 11, pp. 1-6, 2011.

[11] N. Daly and M. M. Blakeney-Williams, "Picturebooks in Teacher Education: Eight Teacher Educators Share their Practice," Aust. J. Teach. Educ., vol. 40, no. 3, pp. 89-101, 2015.

[12] S. J. Lamon, "The roles of representation in school mathematics," in From fractions to rational number, 2001, pp. 146-165.

[13] J. Gujarati, Strategies for Successful Learning. New York: Department of Curriculum and Instruction at Manhattanville College in Purchase, 2013.

[14] D. Maher, S. Schuck, and R. Perry, "Investigating knowledge exchange amongst school teachers, university teacher educators and industry partners," Aust. J. Teach. Educ., vol. 42, no. 3, pp. 73-90, 2017.

[15] A. R. Baturo and T. J. Cooper, "Fractions, reunitization and the numberline Representation," in Proceedings of the 23nd Conference of the International Group for the Psychology of Mathematics Education, 1999, pp. 81-88.

[16] T. Plomp and N. M. Nieveen, "An introduction to educational design research," in Proceeding ofthe Seminar Conducted at the East China Normal University, Shanghai, China, 2010, pp. 23-26.

[17] S. Garvis, B. Fluckiger, and D. Twigg, "Exploring the Beliefs of Commencing EarlyChildhood Education Graduate Students:Providing Insights to Improve Teacher EducationPrograms," Aust. J. Teach. Educ., vol. 37, no. 1, pp. 93-105, 2011.

[18] N. U. Bautista, "Investigating the Use of Vicarious and Mastery Experiences in Influencing Early Childhood Education Majors' SelfEfficacy Beliefs," J. Sci. Teacher Educ., vol. 22, no. 4, pp. 333-349, 2011.

[19] R. Rahardi, "Valsiner's Zone Theory as The Teachers' Zone of Proximal Development," in International Seminar and the Fourth National Conference on Mathematics Education, 2011, pp. 25-36.

[20] G. Anthony and M. Walshaw, "No Title," J. Math. Educ., vol. 2, no. 2, pp. 147-164, 2009.

[21] M. M. Flores, "Using the Concrete-Representational-Abstract Sequence to Teach Subtraction with Regrouping to Students at Risk for Failure," Remedial Spec. Educ., vol. 31, no. 3, pp. 195-207, 2010. 
[22] W. Y. Hwang, N. S. Chen, J. J. Dung, and Y. L. Yang, "Multiple Representation Skills and Creativity Effects on Mathematical Problem Solving using a Multimedia Whiteboard System," J. Educ. Technol. Soc., vol. 10, no. 2, pp. 191-212, 2007.

[23] D. Tanisli and N. Y. Kose, "Pre-Service Mathematic Teachers' Knowledge of Students about the Algebraic Concepts," Aust. J. Teach. Educ., vol. 32, no. 2, pp. 1-18, 2013.

[24] J. Bruner, Towards a theory of instruction. Cambridge, MA: Harvard University Press, 1996.

[25] R. Lesh, M. Landau, and E. Hamilton, Conceptual models in Applied Mathematical Problem Solving Research., Acquisitio. New York: Academic Press, 1983.

[26] S. C. Marley and K. J. Carbonneau, "Theoretical perspectives and empirical evidence relevant to classroom instruction with manipulatives," Educ. Psychol. Rev., vol. 26, no. 1, pp. 1-7, 2014.

[27] G. Olympiou and Z. Zacharias, "Making the invisible visible: Enhancing students' conceptual understanding by introducing representations of abstract objects in a simulation," Instr. Sci., vol. 41, no. 3, pp. 575-596, 2013.

[28] D. M. Belenky and L. Schalk, "The Effects of Idealized and Grounded Materialson Learning, Transfer, and Interest: An OrganizingFramework for Categorizing External KnowledgeRepresentations," Educ. Psychol. Rev., vol. 26, no. 1, pp. 27-50, 2014.

[29] S. Sagala, Konsep dan Makna Pembelajaran untuk Membantu Memecahkan Problematika Belajar dan Mengajar. Bandung: Alfabeta, 2010.

[30] J. Bailey, "Mathematical investigations for supporting pre-service primary teachers repeating a mathematics education course," Aust. J. Teach. Educ., vol. 39, no. 2, p. 7, 2014.

[31] S. Yeşildere, "No Title," J. Teach. Educ., vol. 35, no. 6, pp. 76-96, 2010. 